Revista da ANPOLL, nº 4, p. 97-109, jan./jun. 1998

\title{
ESTRUTURA SOCIAL, TÓPICO E INTERAÇÃO: MARCAS NO DISCURSO PEDAGÓGICO*
}

\author{
Kazue Saito Monteiro de Barros **
}

\begin{abstract}
RESUMO: Identifica-se marcas na produção textual escrita de alunos e professores que parecem motivadas pelas pressuposições de conhecimento partilhado/nãopartilhado entre autor e leitor presumido. Os resultados permitem afirmar que estas. marcas são, em parte, determinadas pelas diferentes formas pelas quais autor $e$ leitor se relacionam um com o outro e com seus textos.
\end{abstract}

PALAVRAS-CHAVE: fala e escrita; tópico; marcas interativas.

\section{INTRODUÇĀO: O TEMA}

W as investigações sobre a língua falada, diversas disciplinas discurso, interpretadas como reflexo da posição de um indivíduo numa dada estrutura social. Na maioria dos estudos, é estabelecida uma correlação entre as marcas e as características do sujeito que as produz, sendo mais recente as tentativas de relacioná-las a aspectos da interação verbal. Um dos objetivos deste trabalho é demonstrar, a partir de redações de professores e alunos, que pode existir uma correlação entre a ocorrência de marcas (aqui chamadas interativas) e a natureza da relação autor - leitor presumido.

\footnotetext{
* Este trabalho foi originalmente apresentado no Congresso Nacional da ABRALIN, realizado na Universidade Federal de Alagoas, Maceió, de 12 a 14 de março de 1997.

* * Universidade Federal do Rio Grande do Norte.
} 
BARROS, Kazue Saito Monteiro de. Estrutura social, tópico e interação: marcas no discurso peclagógico.

O tópico, de uma maneira geral e principalmente nos estudos de textos escritos, tem sido mais trabalhado do ponto de vista de sua organização estrutural. Em conformidade com os pressupostos teóricos que embasam meu projeto sobre Organização Tópica e Gêneros Textuais na Fala e na Escrita $^{1}$, no qual este trabalho se insere, persegue-se aqui, uma perspectiva mais interacionista no tratamento do tópico, que vá além da análise formal e que seja capaz de dar conta também de textos escritos. Os resultados parecem demonstrar que a forma como o autor se coloca em relação ao tópico pode provocar variações no uso de marcas interativas.

A análise mostra que, não só textos orais como também os escritos apresentam elementos motivados pelas pressuposições do autor a respeito de seu leitor, assim justificando o tratamento do texto escrito como interação.

\section{OBSERVAÇÕES TEÓRICAS E METODOLÓGICAS}

Dada a fase preliminar da pesquisa, não se tem uma idéia clara de tudo que pode ser arrolado sob o conceito de marca interativa. Neste trabalho, o termo se refere a a traços que revelam aspectos dialógicos na escrita. Corresponde, em parte, ao que Gumperz (1984:131) denominou de pistas de contextualização na interação oral² :

means by which speakers signal and listeners interpret what the activity is, how semantic content is to be understood and how each sentence relates to what precedes or follows... Roughly speaking, a contextualization cue is any feature of linguistic form that contributes to the signalling of contextual presuppositions. ${ }^{3}$

1 Subprojeto do Projeto Integrado Fala e Escrita: Características e Usos II, coordenado pelo Prof. Dr: Luíz Antônio Marcuschi (CNPq 523612/96-6).

2 Cumperz refere-se mais a "traços superficiais da forma da mensagem" (1982:131). Neste traballıo não se propōe a identificação de uma série de itens lingǘsticos, pois embora essas marcas se evidenciem formalmente na superfícic textual, clas são vistas como vestígios do processso interacional e é a comprercusão desse processo que constitui o interesse principal da investigação.

3 ... meios através dos quais os falantes assinalam e os ouvintes interpretam qual é a atividade, comono conteúdo semântico deve ser entendido ... De forma geral, uma pista de contextualização é đualıưr característica lingǘstica que contribui para a sinalização das pressuposiçōes contextuais. 
Do ponto de vista da estrutura ideacional, isto é, da transmissão de um conteúdo informacional, as marcas interativas são supérfluas ou digressivas, preenchendo mais uma função interpessoal.

Para esse trabalho, foram inicialmente examinadas cento e vinte redações de professores e alunos:

- trinta textos de professores sobre o tema "a fome";

- trinta textos de professores sobre o tema "a política";

- trinta textos de alunos sobre o tema "festas juninas".

As redações dos professores foram produzidas a pedido do pesquisador durante um curso de especialização que o último administrou $\mathrm{em}$ 1994, na cidade de Encanto. Os professores praticam agricultura de subsistência e se mostram mais familiarizados com o tema "a fome" do que com "a política", já que a área rural do Rio Grande do Norte está sujeita a constantes períodos de seca. O pesquisador é professor universitário, mestrando em Lingüística na UFRN e reside em Natal. Já ocupou vários cargos administrativos na cidade. Os textos dos alunos foram coletados em situação de sala de aula pelo professor, em junho de 1996. Os temas foram indicados pelo pesquisador e repassados aos alunos pelo professor. As crianças são alunos dos professores citados, portanto, de primeiro grau. Suas idades variam de oito a dezesseis anos.

\section{ANÁLISE E RESULTADOS}

As marcas interativas que parecem motivadas pelas suposições do autor sobre o partilhamento/não-partilhamento de conhecimento com seu leitor presumido cumprem diversas funções. No corpus, as mais constantes são: garantir a compreensão que o autor supõc ameaçada; preservar a face do autor; e demonstrar o partilhamento de conhecimento. 
BARROS, Kazue Saito Monteiro de. Estrutura social, tópico e interação: marcas no discurso pedagógico.

Tabela 1: Distribuição das marcas interativas nos 3 grupos de textos.

\begin{tabular}{|l|l|l|l|l|l|l|l|l|}
\hline $\begin{array}{l}\text { Tema/ } \\
\text { autor }\end{array}$ & \multicolumn{2}{|c|}{$\begin{array}{c}\text { Fome/ } \\
\text { Prof. }\end{array}$} & \multicolumn{2}{c|}{$\begin{array}{c}\text { Política/ } \\
\text { Prof. }\end{array}$} & \multicolumn{2}{c|}{$\begin{array}{l}\text { Festas J/ } \\
\text { Aluno }\end{array}$} & \multicolumn{2}{|c|}{ Total } \\
\hline & $\mathrm{N}^{\circ}$ & $\%$ & $\mathrm{~N}^{\circ}$ & $\%$ & $\mathrm{~N}^{\circ}$ & $\%$ & $\mathrm{~N}^{\circ}$ & $\%$ \\
\hline compr. & 16 & 64 & 06 & 13.6 & 01 & 6.2 & 23 & 27 \\
\hline face & 04 & 16 & 31 & 70.4 & 02 & 12.5 & 37 & 43.5 \\
\hline conhec. & 05 & 20 & 07 & 15.9 & 13 & 81.2 & 25 & 29.4 \\
\hline Total & 25 & 100 & 44 & 100 & 16 & 100 & 85 & 100 \\
\hline
\end{tabular}

A análise será no sentido de tentar explicar porque, conforme mostra a Tabela 1: a) a maioria das marcas que aparece no texto do professor sobre a fome tem como objetivo garantir a compreensão; b) a maioria das marcas que aparece no texto do professor sobre política tem como objetivo a preservação da face; e c) a maioria das marcas que aparece no texto do aluno sobre festas juninas tem como objetivo a demonstração de conhecimento partilhado.

Será sustentado que a) os textos sobre a fome, do professor, são dirigidos ao pesquisador. A maioria das marcas visa a garantir a compreensão porque a suposição que o professor faz do conhecimento partilhado/não-partilhado é a de que: eu sei - ele não sabe. Portanto, é preciso tornar os enunciados explícitos para que o leitor entenda corretamente; b) os textos sobre política, do professor, são também dirigidos ao pesquisador. A suposição é a de que eu não sei - ele sabe, daí a necessidade de marcas profiláticas de preservação de face, para que o pesquisador, uma pessoa influente na região, não julgue o autor como incapaz; c) os textos sobre festas juninas, do aluno têm o professor (e alguns também o pesquisador) como leitor(es) assumido(s): a suposição é a de que eu sei ele sabe. A questão aqui é como o aluno pode demonstrar ao professor que sabe. 
Revista da ANPOLL, n 4, p. 97-109, jan./jun. 1998

\title{
2.1. MARCAS DESTINADAS A GARANTIR A COMPREENSÃO: EU SEI - ELE NĀO SABE.
}

\author{
Exemplo 1: Texto 12: Professor, 9/94, pré.
}

$\Lambda$ fome

A fome a tormenta todas as criaturas do mundo principalmente aquelas famílias que vivem na miséria e não tem sua alimentação todos os dias. É triste ver nosso irmãos passando fome enquanto o governo deixa ir para o lixo milhōes e milhōes de toneladas de alimentos. Eu fico tritte quando eu vejo passando na televisão os armazém cheio de alimentos estragados e pelo outro lado o meu vizinho que na casa dele não tem comidas todos os dias, pois ele vive do alugado is to quer dizer trabalho fora para sustentar a família é o pior de tudo não encontra trabalho todo dia....

No Exemplo 1, o autor parece se dar conta de que, possivelmente, seu leitor não irá entender o significado do termo "alugado" c, em conscqüência, a explicação do porquê o vizinho c sua família passam fome. $\mathrm{Ou}$ seja, no momento de formulação, o autor parece ter em mente o próprio pesquisador que, ele reconhece, é de outro nível social e outra região. A suposição aqui ć a de que o leitor não vai entender pelo não-partilhamento do código lingüístico.

Exemplo 2: Texto 01: P, 09/94, 3a e 4" séries.

$\Lambda$ fome

Em 1993 foi um ano muito dificil devido uma seca terrivel, principalmente pra a gente que mora na Zona rural, por que as pessoas que moram na Zona rural a maioria deles só vive do roçado, e não havendo inverno as pessoas que moram no campo passam muila fome.

No ano anterior muita gente passou fome principalmente os agricultores que não tem ajuda de nada. Eu mesma conheci umas famílias que pediu bastante esmola pra alimentar seus filhos, pra não ver eles morrerem de fome. Mais a culpa maior é dos governantes que não se preocupa com a fome do Nordeste, só se preocupam com eles próprios, só olham pra um pobre na época da cleição, c o pior, e que, quem enriquece eles, são os próprios pobres. ... 
BARROS, Kazue Saito Monteiro de. Estrutura social, tópico e interação: marcas no discurso pedagógico.

O tema proposto foi "a fome" e o professor inicia sua composição falando sobre "a seca na zona rural". A relação direta entre estes dois conteúdos (fome - seca) pode ser entendida por alguém da comunidade, mas talvez não seja claro para um outsider que não saiba que as pessoas que moram naquela zona rural a que o autor se refere vivem exclusivamente da agricultura e que a agricultura depende das chuvas. Aqui novamente, o autor parece assumir o pesquisador como leitor. Antevendo um possível ponto de dificuldade pelo fato do pesquisador não ser da área rural, i.e pelo não-partilhamento da comunidade, o autor sente necessidade de acrescentar essa explicação que, do ponto de vista do desenvolvimento do tema, seria supérflua: trata-se de um explicação parentética, podendo-se observar que o enunciado que a segue retoma, semanticamente, o que a antecede.

em 1993 // foi um ano muito dificil devido uma seca terrivel, // principalmente pra a gente que mora na Zona rural,

no ano anterior // muita gente passou fome // principalmente os agricultores

Exemplo 3: Texto 06: P, 9/94, 2" séric.

A Fome

... Muitas famílias passaram fome, a quela fome de amanhecer o dia e

anoilecer so com um pouco dágua, as crianças sofrem. Muitas crianças vinham pra escola choravam com fome, pediam pra ir embora a procura de alimento que não suportava mais a fome. A fome so sabem quem sente. ...

No Excmplo 3, a especificação do termo "fome" se faz necessária para quem não convive com aquela realidade. Mais uma vez, o professor parece ter o pesquisador em mente que, membro de uma classe social superior c habitante da capital, provavelmente não passou por tal experiência e não partilha o conceito "fome". Afinal, "a fome so sabem quem sente." 
Revista da ANPOLL, n" 4, p. 97-109, jan./jun. 1998

Exemplo 4: Texto 06: P, 9/94, 2 séric.

$\Lambda$ Fome

A fome é uma das piores coisa que existe no nosso município.

No ano passado foi um ano muito difícil pra as pessoas que vivem só da agricultura, que morei na zona rural, que dedicam so de roca. A maioria das pessoas no ano passado, foram embora por causa da fome, e por falta dágua. ...

Em 4, a marca interativa evidencia o reconhecimento do não-partilhamento de experiência pessoal entre o autor e o leitor presumido, o pesquisador. O caráter parentético da explicação é reforçado pelas vírgulas e pela retomada do enunciado anterior:

pra as pessoas// que vivem // só da agricultura que dedicam // so de roca

\title{
2.2. MARCAS DESTINADAS A PRESERVAR A FACE DO AUTOR: EU NĀO SEI - ELE SABE
}

Exemplo 5: Texto 56: P, 9/94, 1ª́rie.

\begin{abstract}
A Política
Eu não gosto de política, porque existe muito cambalacho, entre todos os políticos, pois gostam de lazerem promessas e não cumprem.

Como aconteceu comigo que me prometeram uma ajuda e até hoje, nem se quer a cara do candidato nunca mais eu à vi.

Portanto, política existe muita sujeira, muita mentira, nos comícios faltam pouco perder a garganta falando uns dos outros, que não vão fazer isto c aquilo, $\mathrm{c}$ nada se ver de positivo.

Depois que se passa a eleição que vamos cobrar, eles falam meu tempo foi muito pouco não deu para realizar tudo que foi dito.
\end{abstract}

Desculpe, não sci falar de políticos, nem lambém goslo de polílico. 
BARROS, Kazue Saito Monteiro de. Estrutura social, tópico e interação: marcas no discurso pedagógico.

Exemplo 6: Texto 67: P, 9/94, 3a série.

A Política Brasileira

Eu não gosto de política detesto a té em falar, só voto porque é obrigado.

Os políticos só fas subir em palanque e falar prometer tudo, e nada fas para ninguém, quando passa a eleição, não conhece ninguém, por isso cu não sou politiqucira tanto fas.

Não gosto de ir ao comício, para ouvir besteira e prometimento principalmente nesta eleção deste ano para Presidente, Senado, deputado.

Só dou um pouco de valor quanto é eleição para prefeito, que agente conhece e mora aqui, mas esses candidatos que nem conheço.

Desculpe.

Os dois textos (Exemplos 5 e 6) terminam com um pedido de desculpas que, parece óbvio, é endereçado ao leitor, assim caracterizando-se como marca interativa. O leitor assumido é novamente o pesquisador que foi quem propôs o tema. Fica claro, principalmente pelo pedido de desculpas vir ao final do texto, comó uma conclusão, que o professor não considera que tenha cumprido o que the foi pedido, assim indicando que imagina que há mais a ser dito sobre o tema. No Exemplo 5, o autor explicita sua ignorância: não sei falar de políticos, justificando-se: nem também gosto de político.

No Exemplo 6, logo no início de seu texto que o autor indica que não vai poder colaborar de forma satisfatória com o pesquisador: por não gostar de política, cle detesta até em falar: Chama a atenção no corpus a quantidade de textos que começam de forma semelhante a do Exemplo 6 : dos trinta textos analisados, dezesseis (o que corresponde a $53.3 \%$ dos casos) iniciam com afirmação quase idêntica, por exemplo:

Texto 52: Eu não gosto de discutir sobre política porque é um assunto tão chato...

Texto 60: Eu detesto política não gosto nem de ouvir falar...

Texto 63: Não sei de nada sobre política, nuca me enteressi em saber porque não gosto. 
Revisla da ANPOLL, n" 4, p. 97-109, jan./jun. 1998

É preciso relembrar as condições de produção destes textos: as redações foram colhidas no interior de uma instituição acadêmica, a escola; os temas não só foram indicados como foram indicados por alguém superior em termos de nível sociocconômico, cargo e, principalmente, formação acadêmica. Assim, a situação de coleta pode se caracterizar como uma situação de teste. Então, o fato do professor iniciar suas redações com estas afirmações c justificativas parece relevante: é como se fosse uma resposta imediata ao pedido do pesquisador, ao mesmo tempo, prevenindo-o que o tema não será bem desenvolvido. Isso, não porque ele scja mau professor mas porque o tema não é de seu interesse. Desta forma, o professor se resguarda de possíveis críticas por parte do pesquisador, ou seja, preserva sua face negativa (Brown e levinson, 1987).

\subsection{MARCAS DESTINADAS A DEMONSTRAR CONHECIMENTO PARTILHADO: EU SEI - ELE SABE}

Excmplo 7: Texto 118: A, 6/94, 10 anos.

\section{O São João}

Bem, as festas juninas são comemoradas no mês de junho: Eu gosto bastante destas lindas festas.

No dia 13 de junho comemora-se o dia de Santo Antônio, e no dia 24 é o são joão e no dia 29 é o dia de São Pedro.

Todos estas datas comemorativas, são, muito importantes. E por isso que cu gosto destas festas, c acho, também, que todos devem gostar ou melhor, dizendo adorar:

As festas juninas são bastante bonitas, porque tem, danças, comidas, bebidas e tudo mais que vocês sabem.

Nestas festas cu não gosto de estar em casa, mas neste ano cu não fui para nem um lugar, porque, eu não estava muito bem de saúde e não teve nem um jeito pra mim sair de casa.

Mas mesmo assim cu gostei, porque comi bastante milho assado e algumas, pamonhas.

Eu desejo para lodo mundo, que lenham as festas juninas, mais, feliz, do ano e até logo. 
BARROS, Kazue Saito Monteiro de. Estrutura social, tópico e interação: marcas no discurso pedagógico.

A marca a ser comentada é que vocês sabem que é auto-cxplicativa: o autor se endereça diretamente aos seus leitores, professor e pesquisador e explicita que o conhecimento é partilhado. O aluno parece "ler" a atividade como uma situação típica de sala de aula, em que seu conhecimento é testado. Pode-se comprovar, no primeiro e no segundo parágrafos, a preocupação em demonstrar conhecimento fatual sobre o tema: "as festas juninas são comemoradas no mês de junho:"; "no dia 13 de junho comemora-se o dia de Santo Antônio, e no dia 24 é o são joão e no dia 29 é o dia de São Pedro."

Exemplo 8: Texto 99: A, 6/94.

No dia 24 de Junho se comemora o São João com uma animada festa tem muitos comidas ti pigas tais como

Cangica Pamonha milho asado e canzida maria mole pé de moleque.

Em uma festa Junina ninguém fica parado, enquanto algus dançam e se divertem outros paseiam e namoram comem e fazem divesos coisas.

No dia 29 de junio tam bém e comemorado o dia de são Pedro. Já estava me esquecendo do dia de Santo Antônio e nesse dia que comemorando primeira festa Junina o dia deste santo é 13 de Junho.

Essa tês festas Juninas são recebidas com muita animação por todos. Vivam as festas Juninas.

\section{VIVA AO SÃO JOÃO}

Exemplo 9: Texto 107: A, 6/94, 16 anos.

\section{O São João}

... e muito diferendi das outra o são joão toca foguo na fougera e aproveita o arasta pé são joão é certo boaquado tem muita mule ate as moça velha que ta passada que não casa mais esqueci ente os rappais e tocalha na chalcira toca fogu o mes di junho e u mes muito importanti para todo mundo é o mês quitrais muito a legria.

Observe-se que o termo "esquecer", utilizado nos Exemplos 8 e 9, implica a suposição de que há um conteúdo que deve ser tratado. Nova- 
Revisla da ANPOLL, n" 4, p. 97-109, jan./jun. 1998

mente aqui, o aluno se coloca como aquele que está sendo testado, isto é, aquele que deve explicitar um conteúdo que é do domínio do professor.

\section{OBSERVAÇÕES FINAIS}

Retomando as perguntas em relação a distribuição das marcas: a) por que a maioria das marcas que aparece no texto do professor sobre a fome tem como objetivo garantir a compreensão? b) por que a maioria das marcas que aparece no texto do professor sobre a política tem como objetivo a preservação da face? c) por que a maioria das marcas que aparece no texto do aluno sobre festas juninas tem como objetivo a demonstração de conhecimento partilhado?

Nos dois conjuntos de redações dos professores, as marcas são dirigidas ao pesquisador - que é um outsider. "A fome" é um tema mais próximo da realidade do professor que do pesquisador; portanto, é compreensível o professor se colocar como aquele que sabe, inserindo marcas explicativas para que seu leitor compreenda uma realidade que não é a dele. É evidente que falar de política nacional é mais complexo para um professor da área rural do que (o autor imagina) para alguém de classe social mais alta, membro de uma família de políticos influentes na região. Daí a abundância de marcas destinadas a preservação da face.

No caso das marcas interativas dos alunos a explicação é evidente: os alunos lêem a atividade como sendo uma situação de teste, típica da sala de aula. É preciso, portanto, demonstrar conhecimento.

A partir destes resultados, pode-se fazer algumas observações mais gerais.

Primeiro, fica comprovado o point do trabalho: que as marcas são, em parte, determinadas pela natureza da relação entre os participantes e dos participantes com o tópico. Ou seja, que também o texto escrito pode ser analisado em termos de uma estrutura da participação. Mudanças na estrutura podem introduzir variações no texto. 
BARROS, Kazue Saito Monteiro de. Estrutura social, tópico e interaçâo: marcas no discurso pectagógico.

Segundo, que alguns elementos que aparecem no texto (no caso, escrito) não podem ser explicados do ponto de vista de suas funções ideacionais (transmissão de conteúdo) e textuais (estruturas informacionais e concatenação dos elementos). É preciso se deslocar um pouco o foco do conteúdo e das estruturas formais para a observação de outras funçóes, como a função interpessoal (marca relações entre os papéis), funções contextuais (marca a situação c objetivos), processuais (provocadas por ou em consideração a demandas de produção e compreensão do evento, por exemplo, a preocupação com a produção de texto que seja facilmente compreensível).

Finalmente, a terceira e última observação é de natureza metodológica. Como foi visto, todas as marcas eram dirigidas ao pesquisador ou ao professor. Se, por um lado, há uma vasta literatura sobre metodologias de coleta do vernáculo, não há quase discussão sobre os cuidados que o pesquisador deve ter ao tentar obter textos escritos por indução, como foi o caso aqui. Parece que, também para textos escritos, é necessário que se reflita um pouco na metodologia de obtenção destes materiais.

ABSTRACT: In this paper I describe a series of interactive markers identified in students' academic texts. I have deliberately limited the discussion to the markers which seem prompted by the students' pressupositions on shared knowledge between them and their assumed reader - the teacher: The results show that the use of such markers varies according to changes in the participation framework.

KEVWORDS: speaking and writing; topic; interactive markers. 
Revisla da ANP()/L, $n^{\circ}+$, p. 97-109, jan./jun. 1998

\section{BIBLIOGRAFIA}

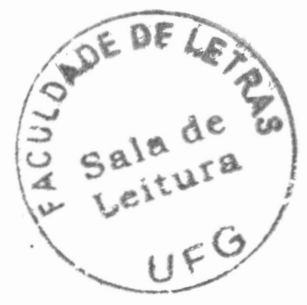

BRONN, P. \&. ILVINSON, S. (1987) Politeness. Some Universals in Language Use. Cambridge: CUP.

CUMIPERZ, J.J. et al. (1984) Cohesion in spoken and written discourse. In: D. Tannen (ed.).

Coherence in Spoken and Wrillen Discourse. Norwood, N.J.: Ablex, p. 3-20. 